\title{
Developing ICT Leadership Skills for Teachers of the Future
}

\author{
Dianne Chambers \\ Science \& Mathematics Education, The University of Melbourne, Australia, \\ d.chambers@unimelb.edu.au
}

\begin{abstract}
There is a strong demand in schools for capable leaders, in particular in the area of the successful integration of information and communication technologies (ICT) into teaching and learning. This need is addressed by an innovative course IT in Primary Schools that prepares our undergraduate students to take on ICT leadership roles in schools. The course is based on a problem based learning approach that utilises the cognitive apprenticeship model. This approach to learning demands that students develop a rich understanding of the complexities of leadership and decision-making about ICT in schools, and the human issues of introducing ICT into a school. Students work in teams, acting as the ICT Committee in a fictional primary school, and solve four large problems over the year. Students develop content knowledge and generic skills, such as information literacy, communication and leadership skills. This approach to learning leads to successful outcomes for students and very satisfying teaching experiences for staff.
\end{abstract}

\section{INTRODUCTION}

The goal of teacher education is to prepare students to be capable teachers - a Herculean task when one considers the large number of roles a teacher plays within a school! Many teacher education courses focus on developing skills and understandings related to the classroom activities of teaching, and do not address the large number of attributes and skills a successful teacher requires when not in the classroom. We have developed an innovative course Information Technology in Primary Schools that is taken by students in the final year of the four-year Bachelor of Education (Primary) degree program. The goal of IT in Primary Schools is to develop our students into the leaders of tomorrow, capable of taking on a leadership role in the area of Information and Communication Technology and, through

The original version of this chapter was revised: The copyright line was incorrect. This has been corrected. The Erratum to this chapter is available at DOI: 10.1007/978-0-387-35701-0_35 
the generic and transferable skills developed, to refine skills for lifelong learning and become a leader in any aspect of a school. We believe that this type of learning cannot be taught through traditional means, and that the PBL approach (Finkle \& Torp, 1995; Stover, 1998) with the cognitive apprenticeship model (Collins, Brown \& Newman, 1989) is a powerful way to facilitate learning about these complex issues and to develop 'habits of mind' that will be beneficial for the students.

\subsection{Teacher education and leadership}

Not many teacher education courses aim to develop leadership skills in pre-service teachers, nor is leadership an issue that many undergraduate education students think about. It is more usual for issues relating to school leadership to be addressed in postgraduate courses that are usually undertaken by school principals or by senior teachers who are aspiring to a principal's position. However, from even the first year as a teacher, new graduates find themselves in a leadership role in a school because of the increase in the decentralized management of schools in Australia. These roles may include serving as a committee member or as chair of a school committee, often making decisions that impact upon the whole school. The leadership roles that have emerged in Australian schools are less a traditional model with hierarchical authority, but more a shared leadership model where decision-making is done as part of a team (Caldwell, 1993; Walker, 1994).

In addition, because of the common perception regarding the ICT expertise of young people, new graduates are being asked to take on roles within a school relating to ICT that, because of their inexperience in schools, they may not have been asked to take on in other areas for a number of years. This means that new graduates are taking on decision-making roles in this area when they may still be quite inexperienced in many aspects of schools. Leadership roles, whether of the traditional or shared leadership models, require a range of skills that few new graduates have developed.

The skills and attributes needed to be a successful leader are congruent with the goals of developing lifelong learning skills and the goals of problem based learning (PBL). Leadership is not always emphasized in PBL, but is an important aspect of this course. The goals for our students include:

- developing the ability to frame questions from complex scenarios;

- identifying and evaluating suitable resources that may help clarify a problem or be useful in developing a viable solution;

- learning to work with other team members and manage human frailties;

- learning ways to be an effective leader and manager of a team;

- preparing documentation with supporting evidence for proposal; and, 
- presenting the essence of the recommendations in a professional and persuasive manner.

In addition to these generic skills the students also learn a vast amount about ICT in schools, including how to effectively include ICT in the curriculum, how to develop and manage an ICT budget, how to design and manage ICT professional development for teachers and for a school, and how to develop a three year ICT plan for a school.

\section{CONTENT OF THE COURSE}

The problems students undertake (in teams) are in the context of decision-making about ICT issues in a fictional primary school - 'Federation Primary School' (named in honour of Australia's Centenary of Federation in 2001). The school and its inhabitants are richly described on the course website. There is a description (with images) of the school, its physical layout, information about the local area, recent school history, children with special needs in the school, staff profile, about the School Council and its members, and other 'factual' information about the school. In addition there is a report from an ICT consultant about current ICT resources in the school, a link to the school's website, and a gossip sheet about the school's staff the sort of information that would never appear in print (but would be common knowledge in the staff room). Also on the course website are links to readings and resources relevant to the problems and details about required outcomes for the problem. Students have email access to experienced teachers in schools who are in ICT leadership positions. The mentoring of our students by practising teachers is seen to be very beneficial. Through tackling the problems students develop a deep understanding of the issues relating to ICT in the school, the 'mechanics' of implementing ICT in a school, and the intricacies of managing a group of individuals, each with preferences and prejudices (such as resistance to change), strengths and weaknesses.

The course is timetabled for a two-hour block each week over two semesters (total of 18 weeks). Students explore each problem over a fourweek period in the following way:

- Introduction to the problem [Week 1]. Teaching staff clarify any issues and respond to questions. Teams start on the problem.

- Student teams work on problem [Weeks $2 \& 3$ ]. Staff are available to mentor and coach teams; practising teachers are available via email.

- Student teams present their recommendations to School Council [Week 4]. Guests are invited to attend and teams also take on a role as a member of the School Council and ask questions from that point 
of view (such as a parent of a child with special needs). A written document with details and data accompanies each presentation.

The content that students explore is accessed through four problems:

- ICT in the Curriculum,

- Developing an ICT Budget,

- Developing ICT Professional Development Plans, and

- Developing a Three-year ICT Plan for a School.

Nothing is taught about these topics, rather, for each problem a brief introduction to the problem is given and there is the opportunity for students to ask any questions or for clarification. The students then work in teams and decide for themselves what resources they should access to best solve the problem. Staff are available to guide students, and practising teachers are available to contact as mentors. A list of resources is provided as a starting point for the students for each problem. The four topics were decided upon through observation of the issues that many schools were experiencing and, often, struggling with. The four problems were identified as topics of ongoing importance for schools through our observations of schools and discussions with postgraduate students (many of our postgraduate students are the ICT coordinator at their school) and others. Much of the knowledge developed through these problems is also directly transferable to other aspects of a school. For example, if you know how to develop a successful ICT Budget, then you are capable of developing a budget for many other aspects of a school, just as a person who has taken into consideration the issues of developing an ICT professional development program for each staff member can transfer those skills to developing a professional development program focusing on other curriculum areas.

Throughout the course in addition to the domain knowledge that students develop there is a strong focus on developing transferable or generic skills such as information literacy skills, team skills, and leadership skills. As with all areas of learning we do not 'teach' any of these things but rather, through the course's design and implementation, we facilitate the students constructing their own knowledge in these areas.

\subsection{Constructivist approach to learning}

This course is underpinned by a constructivist approach to learning. We support students' learning through a very rich learning environment, an important component of which is the richness and authenticity of the fictional school in which the problems are set. Developing the fictional school was a large undertaking, with contributions from a small team with expertise in the area to ensure that the scenario was adequately complex and reflects a range of issues that are typical in a school. The problems set in this school require that students explore below the surface, engaging deeply with 
complex issues of the school environment and its personnel.

Very little, if anything, is 'taught' by staff to the students, but a great deal is learned by students who participate in this course. This style of teaching and learning is not usual in the degree program in which this course is situated, so there was much to be learned by both students and staff about this new way of learning. The shared exploration of passing full responsibility for learning to the students and the expression of concerns on both sides helps bond the group and enables further risk-taking in learning. The openness on the part of teaching staff in expressing any concerns they feel also helps model to students how even experienced teachers may feel anxious when trying out new approaches in their teaching.

\subsection{PBL and the cognitive apprenticeship model}

A PBL approach to learning that utilizes the cognitive apprenticeship model developed by Collins, Brown and Newman (1989) is implemented in this subject to support student learning and to help students develop the 'habits of mind' that will benefit them in their professional lives. Collins, Brown, and Newman's cognitive apprenticeship model (1989) of the learning environment includes:

- Modelling

- an expert carries out the task so that students can observe and build a conceptual model of the processes required to accomplish the task.

- Coaching

- teaching staff observe students while they carry out a task and offer hints, scaffolding, feedback, modelling, and suggest new tasks aimed at bringing the student's performance closer to expert performance.

- Scaffolding and Fading

- scaffolding: supports teacher provides to help students perform task.

- fading: gradual removal of supports until students are on their own.

- Articulation

- students articulate their knowledge, reasoning, or problemsolving processes.

- Reflection

- students compare their problem solving (and, in this case, learning) processes with those of other students, an expert, and, ultimately, their internal cognitive model of expertise. 
- Exploration

- students solve problems on their own.

Through these approaches to learning our students gain knowledge, experience, and confidence in tackling the kinds of issues that they are likely to encounter when in a school leadership role. They also develop and practice leadership skills in managing the team to prepare a detailed report and present recommendations to the School Council. Students develop content knowledge relating to ICT in schools, the generic skills expected of a graduate, an ability to frame questions from an ill-defined scenario, an understanding of how to lead a team to achieve an outcome, and confidence in their ability to handle people, new situations, and challenges.

\section{EVALUATION}

\subsection{End of course evaluation}

The End of Course Evaluation (Table 1) was developed by Samford University's PBL Initiative group (Samford University, 1999) based on a review of the PBL literature. As a pilot study, 12 students completed the survey at the conclusion of the course in 2001 and scored each question on a five-point Likert-type scale, where a response of 'Strongly Agree' scored 5 and 'Strongly Disagree' scored 1. This subject scored between 4.8 and 5.0 on a five-point scale for all questions, which indicates that this approach to learning in this subject was very successful for these students.

Table 1. Mean student responses to questions from the Samford PBL Initiative's End of Course Evaluation questionnaire $(\mathrm{N}=12)$. [Likert-type scale where 'Strongly Agree' scored 5 and 'Strongly Disagree' scored 1.]

\begin{tabular}{lc}
\hline & Mean Score \\
\hline This subject increased my ability to solve real-world problems & 4.8 \\
This subject encouraged me to consider alternatives when solving problems & 4.9 \\
This subject improved my ability to identify appropriate resources & 4.9 \\
This subject improved my ability to work effectively on a team & 5.0 \\
This subject encouraged me to take an active role in my learning & 4.9 \\
I have used knowledge \& methods drawn from outside this subject to complete & 4.9 \\
my subject assignments & \\
\hline
\end{tabular}

\subsection{Student reflections}

The following quotations from students indicate the value that they found in this approach to teaching and learning and how it impacted on them. Of 
particular note is the number of comments on changes in the student's confidence, both personally and professionally, that were a consequence of this course. Below are some comments made at the conclusion of the course.

IT in Primary Schools enabled me to develop as an individual and professional immensely...

I thoroughly enjoyed the challenges presented within the subject and have grown a great deal in my professionalism and attitude toward teaching.

These comments from students' reflective writing indicate the very powerful outcomes when using PBL and the cognitive apprenticeship model are applied as part of the learning process.

At the conclusion of the course students were also asked (among other things) to reflect on the most important things they had learnt in the course. In addition to numerous comments about content knowledge developed, many students commented on the independent learning skills they had developed. The following are some quotations from student reflections:

At the beginning, I found that researching for the problems was a real struggle for me but as we did more problems, I gained a lot of independence and confidence in myself and my own capabilities.

PBL has also helped me develop research skills which have not only benefited me for this subject but also in other subjects throughout my course and I am sure that these skills will be utilised throughout my entire career.

As can be seen, students gain so much more than content knowledge when this approach to learning is used. It is believed that, in particular in an area such as ICT where content knowledge is ephemeral, these skills that make a successful leader and life long learner are of great value and will allow students to continue to update and extend their content knowledge.

\section{CONCLUSIONS}

Problem based learning and the cognitive apprenticeship model applied in this course allow our students to analyse authentic situations in the fictional school and consider alternative solutions while working in a team. It is believed that this approach to learning is very suitable for developing a deep understanding of issues, in this case about ICT in a school, and for developing the skills needed to take on an ICT leadership role in a school. Outside the walls of the university new graduates need to be able to continue to learn, to learn from others, to observe how successful role models behave in achieving their goals, and to be reflective about their own practices, both in and out of the classroom. The approach to learning in this subject prepares 
students for the ongoing learning as professionals as this is how the students learn within the subject. Another very pleasing outcome is that the students are navigators of their own learning. This sense of empowerment is an important aspect for lifelong learning for continued professional development. The approach to learning used in this course expects, indeed demands, that students take responsibility for their own learning and that they hone and refine the skills that will make them successful education professionals and leaders in ICT in tomorrow's schools.

\section{REFERENCES}

Caldwell, B. (1993). Decentralising the Management of Australian Schools: A Discussion Paper. Melbourne: National Industry Education Forum.

Collins, A., Brown, J. S. \& Newman, S. E. (1989). Cognitive apprenticeship: Teaching the craft of reading, writing, and mathematics. In L. B. Resnick (Ed.), Knowing, Learning, and Instruction: Essays in Honor of Robert Glaser (pp.453-494). Hillsdale, NJ: Erlbaum.

Finkle, S. L. \& Torp, L. L. (1995). Introductory Documents. Aurora, IL: Illinois Math and Science Academy.

Stover, D. (1998). Problem-based learning: Redefining self-directed instruction and learning. The Forum, 7(1), 9-10.

Samford University (1999). End of Course Evaluation. Samford PBL Initiative. Retrieved October 11, 2002 from http://www.samford.edu/pbl/ece.html

Walker, A. (1994). Teams in schools: Looking below the surface. International Journal of Educational Management, 8(7), 38-44. 